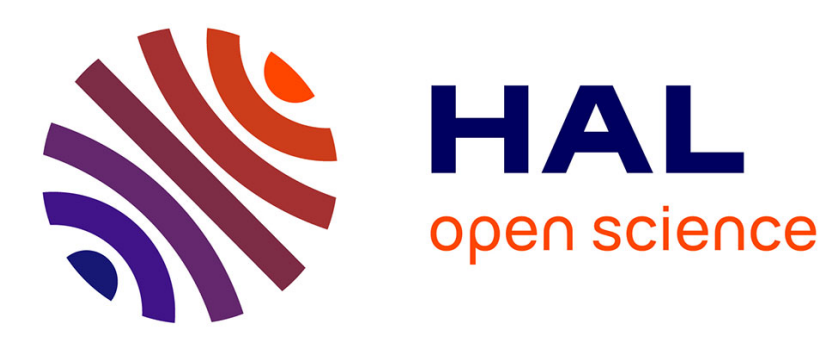

\title{
Vargas Llosa: creatividad y variación léxicas en el español culto
}

Ramon Marti Solano

\section{To cite this version:}

Ramon Marti Solano. Vargas Llosa: creatividad y variación léxicas en el español culto . Observing Norm, Observing Usage: Lexis in Dictionaries and the Media, 2015. hal-01645034

\section{HAL Id: hal-01645034 \\ https://hal-unilim.archives-ouvertes.fr/hal-01645034}

Submitted on 23 Nov 2017

HAL is a multi-disciplinary open access archive for the deposit and dissemination of scientific research documents, whether they are published or not. The documents may come from teaching and research institutions in France or abroad, or from public or private research centers.
L'archive ouverte pluridisciplinaire HAL, est destinée au dépôt et à la diffusion de documents scientifiques de niveau recherche, publiés ou non, émanant des établissements d'enseignement et de recherche français ou étrangers, des laboratoires publics ou privés. 


\title{
Vargas Llosa: creatividad y variación léxicas en el español culto
}

\begin{abstract}
A corpus of newspaper articles by Spanish and Latin-American writers and intellectuals has been collected so as to analyze lexical creativity and variation in Spanish literary and academic register. A sample of lexical items that are not registered in the Diccionario de la Real Academia Española has been extracted. The results of the lexical analysis show different levels of frequency of use as well as various word-formation and neological mechanisms. Particular mention should be made of nominalization (liberticidio) and adjectivization (pesadillesco), negative prefixation (desanimalizar) and loan translations (platitud). Derivation is by far the preferred word-formation process in this language register: in some cases these neological derived words account for geographical variants (Santiago Lacuesta / Bustos Gisbert 1999: 4513) whereas in other cases they are the product of 'crossformation' (Plag 2003: 187), that is potential derivation from a real derived word (rentismo).
\end{abstract}

Key words: lexicography, derivation, neology, loan words, learned words

\section{Introducción}

Este estudio se basa en un corpus de textos escritos en español. Los textos seleccionados son en su totalidad artículos de opinión extraídos de la edición electrónica del diario español El País, que han sido elegidos en función de los propios articulistas, todos ellos escritores, filósofos, profesores universitarios e intelectuales. La razón principal de esta selección es la constitución de un corpus del español culto actual y transnacional que pueda dar cuenta de los rasgos principales de este registro de lengua para todos los hispanohablantes. Tal como ocurre con el registro académico de las ciencias denominadas puras, la medicina y otras disciplinas técnicas, también en la crítica literaria, la 
filosofía, la economía y en las ciencias humanas, sociales y políticas, abundan, entre otros, los fenómenos morfológicos y léxicos tales como la derivación sufijal y los neologismos. Anómico, por ejemplo, representa un caso de adjetivo denominal (de anomia, que en psicología y sociología significa "conjunto de situaciones que derivan de la carencia de normas sociales o de su degradación") no registrado en la actual edición del DRAE (la vigésima segunda, de 2001) pero que aparecerá en la vigésima tercera.

\section{Registro culto del español}

Las características más destacadas del registro culto del español son el empleo de una sintaxis compleja, la inclusión de variados recursos retóricos y, más concretamente en el plano del léxico, la riqueza y precisión léxicas, especialmente en los adjetivos, la abundancia de sustantivos abstractos, los préstamos y calcos de otras lenguas y el recurso tanto a latinismos y helenismos como a neologismos y cultismos en general. Desde el punto de vista morfológico, habría que indicar la abundancia de la derivación adjetival con el sufijo -al y de la derivación nominal con los sufijos -ismo e -ista. Todos estos sufijos son muy productivos y dan lugar a un gran número de derivados, muchos de los cuales, debido a su reciente creación, no están aún registrados ni en diccionarios normativos ni en diccionarios de uso.

De muchos sustantivos pueden derivar formaciones que admiten uno $\mathrm{u}$ otro sufijo, tal es el caso de colaboración y colaboracionista, colaboracionismo, ensayo y ensayista, ensayismo, izquierda e izquierdista, izquierdismo. No siempre es posible la dualidad, pues puede tener vigencia -ista, pero no -ismo (piano y pianista, no *pianismo), o al revés (cristiano y cristianismo, pero no *cristianista). Ambos sufijos gozan de gran vitalidad y crean numerosos neologismos. (Alvar/Pottier 1983: 387)

Finalmente habría que señalar la preferencia en este registro por las variantes ortográficas cultas y especialmente por la prefijación con 
trans- en lugar de tras-, como se observa en numerosos ejemplos de nuestro corpus tales como transformación, transmutar, transgresión, transportador, etc. Otras variantes ortográficas propias de este registro, aunque menos frecuentes, son excrescencia en lugar de excrecencia, substancia en lugar de sustancia y adstringir en lugar de astringir.

A largo plazo nuestro objetivo es el de establecer una caracterización lingüística de este registro de lengua en español a todos sus niveles, desde la sintaxis hasta el léxico y la fraseología, que sea válida para todas las variedades del español y que refleje el estado de la lengua en las primeras dos décadas de este siglo. El objetivo, a corto plazo, no es otro que el análisis de la creatividad y la variación léxicas en este registro de lengua, y más particularmente en el idiolecto del escritor y articulista Mario Vargas Llosa, y de los factores tanto lingüísticos como extra lingüísticos que en ellas intervienen.

\section{Corpus y metodología}

Para este estudio preliminar sobre la creatividad y la variación léxicas en el español culto, creamos un corpus de textos procedentes de los archivos electrónicos del diario español EL País de unas 100.000 formas (97.951 para ser exactos). Aproximadamente dos tercios del corpus está constituido principalmente de artículos de Mario Vargas Llosa. El otro tercio corresponde a textos de otros escritores e intelectuales hispanohablantes. ${ }^{1}$

Seguidamente extrajimos una muestra de elementos léxicos a partir de las formas no reconocidas, y por lo tanto subrayadas, por el corrector ortográfico del procesador de textos. A continuación, aplicamos el criterio de exclusión lexicográfica tomando como referente la $22^{\mathrm{a}}$ edición del DRAE de 2001 pero teniendo también en cuenta el avance de la $23^{\text {a }}$ que aparece en la versión electrónica de

1 Estos son Jorge Edwards, Antonio Elorza, Marta Lamas, Fernando Savater, Carlos Fuentes, Ignacio Sotelo, Daniel Innerarity, Jorge Volpi, Josep Ramoneda y Francisco Bustelo. 
dicho diccionario. De esta manera no hemos incluido en nuestra selección los vocablos meritoriaje, anómico, amedrentamiento, aconfesionalidad, redistributivo y asumible ya que éstos tendrán su propia entrada en la próxima edición del diccionario académico.

El espectro léxico ha resultado ser muy variado y va desde el hápax ${ }^{2}$ angelización hasta palabras tan frecuentes como identitario o internauta. Los vocablos extraídos de nuestro corpus que no están documentados en el DRAE y que aparecen por orden alfabético a continuación son creaciones neológicas, formas derivadas, calcos léxicos $\mathrm{o}$ variantes morfológicas $\mathrm{u}$ ortográficas: absolutizar, acríticamente,aymara, angelización, bestializado, cataclísmico, civilizatorio, contrasubversivo, cortoplacista, culturalidad, desanimalizar, desbrujulado, descriminalización, entrematarse, enturbantar, exaltante, fatalización, gansteril, identitario, idiotización, inasumible, internauta, letrismo, liberticidio, luciferinamente, ludita, multimillonario, narcoestado, neofilia, numantismo, pesadillesco, platitud, provisional, principista, reduccionismo, rentismo, renunciativo, sartreano, situacionismo, totalizante, urbanicidio y violentista.

La gran mayoría de las piezas léxicas de esta selección pertenecen a un registro de lengua elevado o culto, lo que confirma el lazo de unión existente entre este registro de lengua y la neología y derivación afijal. Nos parece pertinente en este contexto hacer referencia a las palabras del profesor Félix Monge sobre la relación causa-efecto entre sufijación y cultismos.

\footnotetext{
La sufijación presenta irregularidades en español y, en general, en las lenguas naturales. Por lo demás, tal carácter-la irregularidad—se extiende al vocabulario en su conjunto. Una de sus causas es la invasión de cultismos [...] De la introducción de cultismos resulta un rejuvenecimiento del idioma. (Monge 1996: 53)
}

Es precisamente esta relación la que hemos podido observar tras el análisis de una parte de nuestra selección léxica. Especialmente

2 Para este estudio, la clasificación de un elemento léxico como hápax les corresponde exclusivamente a las voces que no aparecen registradas ni en el Corpus de Referencia del Español Actual (CREA) ni en el Corpus Diacrónico del Español (CORDE). 
interesantes son los casos de los derivados nominales en -ismo y en -ista, propios de este tipo de discurso al igual que del discurso académico. El carácter fundamentalmente conceptual del registro culto del idioma lo hace propicio a la abstracción y, por ende, al recurso a formas léxicas aglutinantes (adjetivos denominales como identitario) en lugar de expresiones sintácticas analíticas (sintagmas preposicionales como de/sobre la identidad).

\section{Frecuencia de uso}

En cuanto al análisis de la frecuencia de uso de estos vocablos, hemos recurrido al Corpus de referencia del español actual (CREA) y al Corpus diacrónico del español (CORDE).

Contrariamente a lo que habríamos deseado no hemos podido verificar de manera profunda y exhaustiva la presencia de estos vocablos en la prensa española e hispanoamericana debido a la dificultad para obtener resultados precisos en los archivos electrónicos de los periódicos con respecto a la búsqueda separada de las variaciones de número para los sustantivos y de género y número para los adjetivos. No obstante, la presencia, frecuencia y recursividad de estas formas son un signo evidente de su uso en el discurso periodístico en general, algo que hemos podido comprobar gracias al diario español $A B C$, cuyos archivos electrónicos permiten la búsqueda diferenciada, por ejemplo, de las cuatro formas del adjetivo identitario. Por consiguiente, los resultados obtenidos y presentados en el cuadro 1 corresponden al lexema y no a la forma del masculino singular para los adjetivos o a la forma del singular para los sustantivos.

\begin{tabular}{|l|c|c|}
\hline \multicolumn{1}{|c|}{ lexema } & ABC & CREA \\
\hline identitario & 2232 & 63 \\
\hline cortoplacista & 170 & 28 \\
\hline
\end{tabular}




\begin{tabular}{|l|c|c|}
\hline civilizatorio & 46 & 53 \\
\hline gan $($ g)steril & 32 & 66 \\
\hline narcoestado & 30 & 5 \\
\hline cataclísmico & 21 & 12 \\
\hline situacionismo & 19 & 5 \\
\hline pesadillesco & 19 & 18 \\
\hline exaltante & 18 & 39 \\
\hline letrismo & 8 & 9 \\
\hline
\end{tabular}

Cuadro 1. Muestra de frecuencia de uso en ABC y CREA.

La columna de la derecha registra el número total de casos documentados en el CREA, lo que permite cotejar los resultados con los obtenidos en los archivos del diario $A B C$. Es evidente que el recurso a los archivos electrónicos de uno o de varios periódicos puede resultar muy eficaz para determinar la amplitud de ciertos fenómenos léxicos. En el caso que nos ocupa, es interesante resaltar, por poner solo unos ejemplos, la explosión en el empleo de identitario y la diferencia cuantitativa proporcional en los lexemas cortoplacista y narcoestado, seis veces mayor en el archivo periodístico que en el corpus académico. El caso contrario es también posible, como se puede observar en el adjetivo exaltante cuya frecuencia de uso es menor en el periódico que en el CREA.

Se observa, pues, que estos vocablos tienen una frecuencia de uso moderada o poco elevada si exceptuamos el adjetivo identitario. Este último muy probablemente sea un calco del adjetivo francés identitaire, aunque podría también tratarse de un caso de poligénesis por derivación analógica con otros adjetivos como unitario, autoritario o sanitario. Los dos primeros casos documentados en el CREA (ya que no se encuentran casos en el CORDE) corresponden a usos en los que el adjetivo identitario aparece asociado al concepto del nacionalismo, como en "el fenómeno del nacionalismo identitario" (España, 1996) y "los dogmas del nacionalismo identitario" (España, 
1999). También aparece asociado a posturas o posiciones políticas, como en "la multiplicidad de posiciones identitarias" (Puerto Rico, 1996). A partir del año 2000 la combinatoria léxica es mayor y el adjetivo aparece asociado a sustantivos como componente, referente, nexo, etc., lo que demuestra el proceso de institucionalización y lexicalización del neologismo. Finalmente nos gustaría señalar que la hemeroteca electrónica del periódico español La Vanguardia permite la búsqueda de palabras o expresiones desde 1881 hasta la fecha. Resulta interesante, pues, observar que los dos primeros casos documentados en este periódico son de 1990 y que aparecen respectivamente en un artículo traducido del francés sobre las elecciones en Argelia y en una entrevista que el filósofo BernardHenri Lévy le hace, precisamente, a Mario Vargas Llosa, lo que confirmaría la tesis de la influencia francesa de este neologismo. ${ }^{3}$

(1) Ha visto el riesgo que representa para la supervivencia de España y de la democracia el nacionalismo identitario, y ha criticado siempre las concesiones que le han hecho los gobiernos [...]. (V. Llosa)

El ejemplo (1) está sacado de nuestro corpus y refleja, de manera clara y evidente, la connotación negativa o valoración peyorativa asociada a este término, sobre todo en combinación con el sustantivo nacionalismo.

\section{Mecanismos de creatividad y variación léxicas}

Son muchos los mecanismos que dan lugar a formaciones neológicas en español pero aquí nos centraremos en los más destacados en este registro de lengua y, más concretamente, en nuestro corpus. La

3 Es interesante constatar que el adjetivo francés identitaire no aparece registrado en el gran diccionario Le trésor de la langue française informatisé (TLFi). Sin embargo, Le Petit Robert, en su edición de 2013, registra este adjetivo y lo define de la manera siguiente: "Qui est relatif à l'identité. Quête, crise identitaire." 
derivación afijal es sin duda alguna el mecanismo de formación de palabras más importante. Aunque hemos observado casos de derivación verbal e incluso algunos derivados adverbiales, son la derivación nominal y la derivación adjetival las que se llevan la palma. Otros mecanismos recurrentes son la prefijación negativa, la formación analógica, los calcos léxicos y los casos de variantes morfológicas y ortográficas.

\subsection{Derivación nominal}

En lo que se refiere a la morfología derivativa, la derivación nominal es un elemento fundamental y un mecanismo de formación de palabras frecuente en este registro. La expresión, el desarrollo y el análisis minuciosos de ideas, puntos de vista y opiniones, propios de este tipo de textos, implica, entre otros fenómenos linguí́sticos, la necesidad de emplear sustantivos abstractos que se adapten mejor al nivel de pensamiento y al grado teórico que alcanza el discurso.

El DRAE define liberticida como el "que mata o destruye la libertad" pero no registra el término liberticidio. El paradigma de sustantivos derivados con el sufijo -cidio en español es muy limitado y comprende los siguientes elementos: suicidio, homicidio, genocidio, infanticidio, parricidio, matricidio, fratricidio, regicidio, magnicidio, tiranicidio y uxoricidio. En todos estos casos la base tiene el rasgo semántico [humano], a diferencia de lo que ocurre con liberticidio o urbanicidio en donde este rasgo semántico está ausente. ${ }^{4}$

(2) $[\ldots]$ hay un abismo, que, si lo abolimos, podría significar, no una hazaña libertaria sino pura y simplemente un liberticidio que, además de socavar los cimientos de la democracia, infligiría un rudo golpe a la civilización. (V. Llosa)

4 Incluso si en el caso de magnicidio la base corresponde al adjetivo magno, éste tiene como referente a una "persona muy importante por su cargo o poder". 
(3) El urbanicidio más triste es el de la Casa Eguiguren, seguramente la de mayor prestancia e historia de la ciudad, desfondada, desenrejada, saqueada de sus azulejos, de su artesonado, de sus puertas con clavos y convertida en un amasijo de ruinas pestilentes. (V. Llosa)

Si partimos de la base de que la existencia de la acción en este paradigma léxico implica necesariamente la existencia del agente y viceversa (homicidio > homicida, fratricida > fratricidio), esto explicaría la creación del sustantivo liberticidio ("acción cometida por un liberticida") y su uso en el ejemplo (2). El caso de urbanicidio resulta mucho menos evidente puesto que el nombre de agente urbanicida no existe como palabra real. Podemos hablar aquí de una especialización semántica del contenido del conjunto del neologismo que, tal como aparece en (3), designa "el atentado y la degradación o destrucción de un bien patrimonial arquitectónico urbano de elevado valor histórico-artístico".

Al igual que ocurre con liberticida, el DRAE consagra un artículo al vocablo rentista que define como la "persona que percibe renta procedente de una propiedad de cualquier tipo" pero no registra el sustantivo posible rentismo, que nos atreveríamos a definir como "actitud del que vive exclusivamente de sus rentas" y cuyo uso se ilustra en el ejemplo (4):

(4) Contra una izquierda dura, $[\ldots]$ y contra una derecha conservadora y ultra, acomplejada y acobardada frente a la izquierda, desconfiada del mercado y la apertura económica, favorable al rentismo y con más intereses que convicciones y principios. (V. Llosa)

El mismo tipo de creación léxica se presenta en el caso de numantismo en (5), en realidad una variante morfológica de la palabra real numantinismo o incluso un caso de doblete derivativo del tipo sintactista/sintacticista o independista/independentista. El DRAE define numantino como alguien "que resiste con tenacidad hasta el límite, a menudo en condiciones precarias" y numantinismo como el sustantivo deadjetival que indica la "actitud".

$5 \quad$ La definición de urbanicidio es nuestra. 

fortín militar inexpugnable, capaz de pulverizar en caso de amenaza a todo su entorno- [...], son políticas suicidas, que ponen en peligro la supervivencia de Israel. (V. Llosa)

Ingo Plag introdujo en el campo de la derivación el término crossformation, curiosamente una formación analógica sobre la base del concepto back-formation, conocido en lexicología y morfología españolas como retroformación. Se trata de un mecanismo que permite la creación de palabras en cualquiera de los dos sentidos, a diferencia de lo que ocurre con la retroformación. De este modo, se podría explicar la existencia de derivados potenciales a partir de derivados existentes, tal como se ilustra en la siguiente cita: "Every (potential) word with the suffix -ist has a corresponding (potential) word in -ism" (Plag 2003: 187). Así, la existencia de una palabra real como rentista implicaría automáticamente una palabra no realizada pero posible como rentismo.

\subsection{Derivación adjetival}

La derivación adjetival es, junto con la derivación nominal, el mecanismo más destacado de creatividad léxica en el registro culto del español, lo que no es de extrañar puesto que "[c]on sus más de 70 sufijos, la categoría derivacional de los adjetivos de relación (o relacionales) es la más importante numéricamente del español." (Rainer 1999: 4611).

Especial atención merecen los adjetivos en -ista, sufijo que goza de gran vigor y que es extremadamente productivo. El adjetivo denominal principista aparece en el CORDE con sólo 5 casos y en el CREA con 25. Para ilustrar su uso y significado hemos seleccionado la siguiente cita de las memorias de Pablo Neruda: 

consultaba todas sus medidas. Fue el antidictador, el demócrata principista hasta en los menores detalles. (Pablo Neruda 1973: 475)

Es evidente que el adjetivo en (6) sustituye al complemento del nombre "de principios" tal como se utiliza, por poner un ejemplo, en el compuesto sintagmático "hombre de principios". Observamos pues en (7) el empleo del mismo adjetivo, en esta ocasión tal como aparece utilizado en un texto procedente de nuestro corpus:

Savater me ha parecido siempre un modelo de intelectual comprometido, a

la vez principista y pragmático, uno de esos raros pensadores contemporáneos capaces de ver siempre claro en el intrincado bosque que es este siglo XXI y de orientarnos a encontrar el camino perdido a los que andamos algo extraviados. (V. Llosa)

El sufijo -ista es especialmente productivo en el español americano: de los 25 casos registrados en el CREA del lexema principista, solo uno corresponde a España. Este ejemplo español requiere una interpretación semántica totalmente distinta de la del adjetivo americano ya que se emplea en el contexto histórico de la transición democrática española en oposición al adjetivo juanista. ${ }^{6}$

Por su parte, el adjetivo cortoplacista en (8) constituye un caso especial de univerbación ${ }^{7}$ con cambio de categoría gramatical. De este modo, a partir de la locución adverbial a corto plazo, se han creado en español cortoplacismo y cortoplacista. El adjetivo, ausente en el CORDE, cuenta con 28 casos en el CREA, lo que lo convierte en una formación relativamente reciente: el primer caso documentado es de 1993.

6 Los términos principista y juanista en este contexto corresponden respectivamente a los partidarios del Príncipe Don Juan Carlos y de su padre Don Juan de Borbón, Conde de Barcelona.

7 La univerbación es un mecanismo de formación de palabras según el cual un derivado no es el producto de la morfología sino que se crea a partir de un sintagma o cualquier otra estructura frástica: "Morphology serves to expand the lexicon, the set of established words of a language, but is not the only source of lexical units, and not even that of all complex words, which also arise through borrowing, univerbation and word creation." (Booij 2005: 24). 
(8) Mareado por el poder y la obsesión continuista, peón de brega de los delirios socialistas y bolivarianos del comandante Chávez junto al boliviano Evo Morales y el nicaragüense Daniel Ortega, el gobierno de Rafael Correa, con sus políticas cortoplacistas, de irresponsabilidad fiscal y corrupción multiplicada [...] (V. Llosa)

El Diccionario de Americanismos (DA) define violentista como "Referido principalmente a persona, partidaria del uso de la fuerza para imponer sus ideas sociopolíticas".

(9) Todo ello ha ido imponiéndose poco a poco, por la fuerza de las cosas, a través de la evolución de una derecha y una izquierda que, no sin reticencias y traspiés, han ido renunciando a sus viejas obsesiones excluyentes y violentistas, y cambiando de métodos. (V. Llosa)

La derivación morfológica en (9) es, cuando menos, especial ya que el adjetivo en -ista no se forma a partir del sustantivo correspondiente, violencia (lo que habría dado *violencista), sino a partir del adjetivo violento. Además, este sufijo, que se utiliza fundamentalmente para crear sustantivos agentivos (flautista, periodista), puede formar también adjetivos generalmente sobre la base de nombres de políticos (la Policía política salazarista) (Rainer 1999: 4622), lo que no se observa en absoluto en este caso. Se trata pues de un caso particular de derivación que da lugar a un "adjetivo adjetival".

\subsection{Prefijación negativa}

Resulta interesante observar cómo un número importante de creaciones léxicas en el español culto corresponde a derivados afijales por prefijación negativa. $\mathrm{Si}$ nos centramos en el adverbio acríticamente, observamos que hay 29 casos en el CREA y 3 en el CORDE, siendo el primero de estos de 1965 y de España. Los otros 
casos se reparten de forma equitativa entre España e Hispanoamérica. Se trata, pues, de un derivado no marcado diatópicamente.

Señalemos también el caso de inasumible, derivación afijal homogénea a partir del adjetivo asumible. Este último, tradicionalmente excluido en el diccionario académico, dispondrá por primera vez de su propia entrada en la $23^{\mathrm{a}}$ edición del DRAE. Por consiguiente, hay que pensar que inasumible gozará en el futuro del mismo derecho de ciudadanía que su correspondiente adjetivo positivo.

Existe, pues, una tendencia al empleo de un adjetivo derivado en este tipo de registro en lugar de las estructuras frásticas "no se puede asumir" o "resulta imposible asumir", como sería de esperar en otros tipos de discurso o registros de lengua.

Los ejemplos en (10) y (11), por su parte, representan casos de prefijación negativa sobre la base de los verbos reales animalizar y criminalizar.

(10) Así fue surgiendo la libertad, desanimalizándose el hombre, naciendo de verdad la humanidad del ser humano. (V. Llosa)

(11) Esta solución pasa por la descriminalización de las drogas, idea que hasta hace relativamente poco tiempo era inaceptable para [...]. (V. Llosa)

\subsection{Calcos léxicos}

El uso de calcos léxicos es hasta cierto punto explicable en alguno de los escritores e intelectuales por el conocimiento profundo y el contacto directo y prolongado que han tenido con lenguas extranjeras. Recuérdese que Vargas Llosa vivió y trabajó durante mucho tiempo en París y también en Londres y que, igualmente, Jorge Edwards comenzó su carrera diplomática en París y que es actualmente el embajador de Chile en Francia. Los tres ejemplos seleccionados en esta sección son de Vargas Llosa. En primer lugar tenemos un calco de 
la palabra francesa o inglesa platitude que en español significa "trivialidad" o "tópico", como se puede observar en (12). En realidad se trata de una cita de Jorge Luis Borges, otro escritor e intelectual con un conocimiento profundo no solo del inglés y del francés sino de muchas otras lenguas, incluida el islandés. A continuación se observa en el ejemplo (13) el uso de la voz desbrujulada, calco del adjetivo participial francés déboussolée (derivado del sustantivo boussole, que significa "brújula") y que podría traducirse como "desnortada" o "desorientada". En tercer lugar, y en el ejemplo (14) aparece otro calco, el verbo pronominal entrematarse. Creado a partir del verbo francés s'entretuer, su interpretación semántica es transparente y su significado podría glosarse como "matarse unos a otros" o "matarse entre sí o mutuamente". Los únicos dos casos de la forma del infinitivo de este verbo en el CREA son también de Mario Vargas Llosa, lo que nos lleva a pensar que podría tratarse de un rasgo propio de su idiolecto. ${ }^{8}$

(12) Algo similar acontece con los muchos volúmenes de su prosa. Forman un caos de intuiciones geniales, de platitudes, de sofismas, de moralidades ingenuas, de inepcias y de plagios". (V. Llosa)

(13) Probablemente, [...] la Iglesia terminaría por desintegrarse desde adentro, por convertirse en una comunidad caótica, desbrujulada, a causa de las luchas intestinas y las querellas sectarias. (V. Llosa)

(14) Los repetidos fracasos [...] han ido empujando a las sociedades latinoamericanas hacia el realismo, es decir, hacia los consensos democráticos, el primero, el de coexistir en la diversidad política sin entrematarse, acatando los veredictos electorales, [...] . (V. Llosa)

\footnotetext{
8 Ninguna de estas tres piezas léxicas aparecen en el Diccionario de galicismos del español peninsular contemporáneo (DGEPC) ni en el Diccionario de americanismos (DA). Sin embargo, el verbo entremeterse lo registra el Diccionario del español actual (DEA) que proporciona como ejemplo una cita de Goytisolo, lo que demuestra que la utilización del CREA no es suficiente para delimitar, entre otros muchos fenómenos, aspectos idiolectales
} 
Ni desbrujulado ni entrematarse están registrados en el Diccionario de galicismos del español peninsular contemporáneo (DGEPC) ni en el DA, lo que corroboraría la tesis de su carácter de calcos léxicos propios de este tipo de registro o nivel de lengua.

\subsection{Variantes morfológicas}

Según el DRAE el verbo totalizar significa "determinar el total de distintas cantidades" y totalizador, "que totaliza". Hay que destacar aquí que el primer caso documentado de totalizante en el CORDE es de España, de 1946, y que aparece en un texto filosófico, "Ideario de San Agustín" de Agustín Martínez. Los otros casos corresponden a textos etiológicos o antropológicos. Se trata, pues, de una derivación afijal con marcado carácter diastrático (15), lo que confirma que "[1]os adjetivos participiales en -ente o -ante en español se consideran cultismos." (Alvar y Pottier 1983: 391)

(15) Cada uno de ellos encierra sin duda una parte razonable, pero su utilización totalizante está destinada a paralizar la discusión (“¿no me irá usted a negar que...?”) en lugar de a favorecerla. (Savater)

Observemos ahora el caso del adjetivo civilizatorio. A diferencia de totalizante, no existen casos del adjetivo civilizatorio en el CORDE, lo que demuestra su relativa novedad. Hemos encontrado 53 casos del lexema civilizatorio en el CREA. Consideramos que cuando se produce una alternancia entre sufijos que reflejan idénticos contenidos semánticos, el derivado más reciente puede adquirir un valor colocacional al entrar en asociación léxica con un sustantivo de manera recurrente. La combinación proceso civilizatorio registra un total de 10 casos, un número proporcionalmente más que suficiente para pensar que se trata de un fenómeno más bien fraseológico que morfológico. 
Sabemos que la sinonimia afijal completa es muy rara o casi inexistente y que en el caso de que ésta se produzca, la distinción es normalmente diatópica y corresponde a la preferencia del español de España y del español de América. Financiacion y minoría son las formas preferidas en Espada mientras que financiamento y minoridad lo son en América. En muchos otros casos, la diferencia afijal corresponde a una acepción o a un matiz semántico distintos, como se puede apreciar en el doblete convicción/convencimiento en donde convicción ha adquirido una acepción particular de "idea religiosa, ética o política fuertemente arraigada".

\section{Análisis lexicográfico}

Hemos utilizado el Diccionario de neologismos de la lengua española (DNLE) para comprobar si alguno de los elementos léxicos de nuestro corpus está documentado o si aparece con una variante en este lexicón. Solo dos derivados nominales en -ismo, reduccionismo y rentismo forman parte de la nomenclatura de este diccionario que los define respectivamente como "Tendencia a simplificar los enunciados o fenómenos complejos" y "Obtención de beneficios o ventajas de la hacienda publica". Además de estos dos sustantivos el DNLE incluye el adjetivo gangsteril, aunque no su variante gansteril.

Parecería normal que los diccionarios de uso registrasen muchas de las formas que no aparecen en el diccionario académico. Así, el Diccionario del Español Actual (DEA) registra solo las formas idiotizacion e identitario. Por su parte, el DA recoge algunas de las voces, aunque muy pocas, como por ejemplo violentista, provisional y por el contrario no registra el americanismo principista.

\section{Conclusiones y perspectivas}


La derivación morfológica es, sin ninguna duda, el mecanismo privilegiado de formación de palabras en este registro de lengua, fundamentalmente la sufijación adjetival en -al e -ista y la nominal en -ismo. Estos neologismos derivativos reflejan en algunos casos aparcadas preferencias diatópicas, como en el caso de principista, derivado de uso exclusivo en el español de América. Otros son el producto de cross-formations, o sea derivados potenciales a partir de un derivado existente (rentista > rentismo). Conviene asimismo señalar el carácter sintético de algunas de las formas neológicas (inasumible, absolutizar) empleadas en lugar de otras estructuras frásticas equivalentes. Finalmente, destacaríamos el uso creativo de nombres abstractos, fundamentalmente cultismos, tales como letrismo, neofilia o reduccionismo, que pueden ser o creaciones independientes o calcos léxicos, estos últimos relativamente frecuentes y que pueden ser adscritos al idiolecto de un escritor o intelectual concreto.

Finalmente sería interesante cotejar las particularidades léxicas de Vargas Llosa en su producción periodística con un estudio en un corpus literario del mismo autor.

\section{Bibliografía}

ABC. In <http://www.abc.es/>

Alvar, Manuel / Pottier, Bernard 1983. Morfología histórica del español. Madrid: Gredos.

Asociación de Academias de la Lengua Española, 2010. Diccionario de americanismos. Lima: Santillana.

Booij, Geert 2005. The Grammar of Words. Oxford: Oxford University Press.

Curell Aguilà, Clara 2009. Diccionario de galicismos del español peninsular contemporáneo. Estrasburgo: Editions de linguistique et de philologie. 
El País. In <http://elpais.com/>.

La Vanguardia. In <http://www.lavanguardia.com/index.html>.

Rey-Debove, Josette / Alain Rey (dirs) 2013. Le Petit Robert. Paris: Le Robert.

Le Trésor de la Langue Française informatisé. In $<$ http://atilf.atilf.fr/tlf.htm>.

Martí Antonín, María Antonia / Climent Roca, Salvador 1998. Diccionario de neologismos de la lengua española. Barcelona: Larousse.

Monge, Félix 1996. Aspectos de la sufijación en español. Revista Española de Lingüística. 26/1, 43-56.

Neruda, Pablo 1993. Confieso que he vivido. Memorias. Barcelona: Seix Barral.

Plag, Ingo. 2003. Word-Formation in English. Cambridge: Cambridge University Press.

Rainer, Franz 1999. La derivación adjetival. In Bosque, Ignacio / Demonte, Violeta (dirs) Gramática descriptiva de la lengua española. Madrid: Espasa, 4595-4643.

Real Academia Española: Banco de datos (CORDE). Corpus diacrónico del español. In <http://www.rae.es>.

Real Academia Española: Banco de datos (CREA). Corpus de referencia del español actual. In <http://www.rae.es>.

Real Academia Española: Diccionario de la lengua española. In <http://www.rae.es>.

Santiago Lacuesta, Ramon / Bustos Gisbert, Eugenio 1999. La derivación nominal. In Bosque, Ignacio / Demonte, Violeta (dirs) Gramática descriptiva de la lengua española. Madrid: Espasa, 4506-4594.

Seco, Manuel 1999. Diccionario del español actual. Madrid: Aguilar. 